ISSN 1112-9867

Available online at

http://www.jfas.info

\title{
RAPID EXTRACTION OF VOLATILE COMPOUNDS FROM CITRUS FRUITS USING A MICROWAVE DRY DISTILLATION
}

\author{
M.A. Ferhat ${ }^{1, *}$, M.N. Boukhatem ${ }^{2}$, M. Hazzit ${ }^{3}$, F.Chemat ${ }^{4}$
}

${ }^{1}$ Laboratoire de Recherche sur les Produits Bioactifs et la Valorisation de la Biomasse

LPBVB, Ecole Normale Supérieure Vieux Kouba ENS BP 92 Kouba- Alger, Algeria.

${ }^{2}$ Département de Biologie et Physiologie Cellulaire, Faculté des Sciences de la Nature et de la Vie, Université Blida 1, Blida, Algeria.

${ }^{3}$ Département de Technologie Alimentaire, Ecole Nationale Supérieure Agronomique (ENSA), El-Harrach, Algeria.

${ }^{4}$ UMR A 408 INRA, Université d'Avignon, Sécurité et Qualité des Produits d'Origine Végétale, 33 Rue Louis Pasteur, 84029 Avignon cedex 1, France.

Received: 23 March 2016 / Accepted: 23 August 2016 / Published online: 01 September 2016

\begin{abstract}
:
Three different extraction methods were used for a comparative study of essential oil (EO) from fresh Citrus peels: Traditional hydrodistillation (HD), cold pressing (CP) and innovative microwave 'dry' distillation or microwave-accelerated distillation (MAD). The microwave process offers significant advantages over conventional alternatives, viz. shorter distillation period (30 min vs. $3 \mathrm{~h}$ for hydrodistillation and $1 \mathrm{~h}$ for cold pressing); better yields $(0.24 \% \mathrm{vs}$. $0.21 \%$ for $\mathrm{HD}$ and $0.054 \%$ for $\mathrm{CP}$ ); environmental impact (energy charge is noticeably superior for performing $\mathrm{HD}$ and for mechanical motors $(\mathrm{CP})$ than that necessary for quick MAD assay); cleaner features (as no remains creation and no solvent or water used); raises antibacterial properties ; and offers a more precious EO (with high amounts of oxygenated compounds).
\end{abstract}

Keywords: Microwave extraction; Hydrodistillation; Cold pressing; Essential oil; Citrus.

Author Correspondence, e-mail: ferhatamine100@yahoo.fr

doi: http://dx.doi.org/10.4314/jfas.v8i3.6 


\section{INTRODUCTION}

Certains historiens ont souligné : 'La maîtrise du feu représente sans doute l'une des plus vieilles découvertes chimiques et celle qui a le plus profondément bouleversé la vie de l'homme'. On pourrait avancer des intentions identiques pour le chauffage micro-ondes: premier procédé de chauffage radicalement nouveau depuis la découverte du feu. Le passage de cette technique de la cuisine vers le laboratoire de chimie, à des fins d'extraction et de synthèse, a nécessité plus de 40 années de maturation et de recherches. Les chercheurs ont montré qu'il est possible de diminuer d'une manière considérable les temps d'extraction et de réaction, et l'hypothèse d'une 'activation micro-ondes' a été appuyée dans certains cas. Bien que l'industrie chimique utilise des procédés utilisant les propriétés thermiques spécifiques aux micro-ondes comme la vulcanisation des polymères et le traitement des acides, l'utilisation des micro-ondes à des fins d'extraction reste inexistante.

A l'heure actuelle, il est devenu compliqué de découvrir une technique en industrie ou en recherche qui, directement ou indirectement, n'utilise pas les techniques de distillation. La recherche scientifique et technique dans ce volet ne cesse d'augmenter afin de mettre au point ou créer des techniques modernes et aussi plus effipeauffinées en terme de diminution de temps, de rendement et de sélectivité, mais aussi pour œuvrer vers une chimie « verte » utilisant moins de solvant, moins d'énergie et diminuant les rejets.

L'extraction sans solvant assistée par micro-ondes (ESSAM) est une technique récente. Inspirée d'un ancien procédé de distillation dite « sèche » utilisé par les alchimistes arabes pour la distillation des HE, elle consiste en une distillation sèche à l'aide d'un alambic utilisant le soleil comme source de chaleur. L'ESSAM a été développée en remplaçant l'énergie solaire par un chauffage micro-ondes plus performant, plus spécifique et largement moins polluant qu'un chauffage traditionnel.

L'objectif de ce travail était d'étudier un nouveau procédé de distillation des HE assistée par micro-ondes [1-2] et de l'appliquer aux variétés d'agrumes algériennes. Nous avons choisi la variété de citron «Eurêka » comme modèle pour l'étude détaillée de l'extraction de l'HE d'écorce assistée par micro-ondes. Pour cette variété d'agrume, seront passés en revue le rendement, la composition de l'huile essentielle, son activité anti-microbienne et l'analyse 
sensorielle.

L'Algérie est reconnue pour la qualité supérieure de ses agrumes ainsi que pour son savoir faire tant dans la sélection des espèces que dans la production de fruits, de jus et des huiles essentielles d'agrumes. Dans ce travail, nous proposons une nouvelle méthode de récupération des huiles essentielles, avec un double but: la valorisation des déchets de l'industrie des agrumes et la confirmation du caractère innovationnelle technologique de cette méthode dans la chimie extractive. A partir du prototype d'extraction assistée par micro-ondes mis au point au sein du Centre de Recherche Scientifique et Technique en Analyses Physico-Chimiques, une nouvelle méthode d'extraction, sans solvant organique, utilisant les micro-ondes comme source de chauffage a été validée par des essais expérimentaux [3] sur une matrice d'agrumes.

\section{RÉSULTATS ET DISCUSIONS}

\subsection{Extraction de l'huile essentielle de citron « Eurêka » : analyse quantitative}

Le Tableau 1 présente les rendements en huiles essentielles du citronnier «Eurêka » obtenues par extraction sans solvant assistée par micro-ondes, par hydrodistillation et par expression à froid. L'ESSAM est la méthode d'extraction qui fournit la plus grande quantité d'huile essentielle avec un rendement de 0,24\%. L'HD présente un rendement de 0,21\% et l'expression à froid seulement de $0,054 \%$. Ces résultats sont d'autant plus intéressants que la durée d'une ESSAM n'excède pas 30 minutes alors que l'HD et l'expression à froid nécessitent des temps d'extraction de l'ordre respectivement de 180 et 90 minutes.

Tableau 1. Rendement en essence aromatique de la variété Eurêka selon 3 méthodes d'extraction

\section{Rendement de l'extraction (g HE/100g fruits)}

\begin{tabular}{lccc} 
& ESSAM & HD & CP \\
\hline Durée de l'extraction (min) & 30 & 180 & 90 \\
Rendement $(\%)$ & 0,24 & 0,21 & 0,054 \\
\hline
\end{tabular}


Lors d'une ESSAM, la phase de chauffage est relativement faible en comparaison avec l'HD. Cette période de chauffe est toujours de l'ordre de 2 à 3 minutes pour l'ESSAM et de 45 minutes pour l'HD. En revanche, l'étape d'extraction proprement dite durant laquelle les molécules terpéniques volatiles sont effectivement distillées est nettement plus longue (27 à 28 minutes pour l'ESSAM et 3 heures pour l'HD) et se traduit par un palier de température de distillation à $100^{\circ} \mathrm{C}$. La Figure 1 montre aussi bien en ESSAM qu'en HD, l'évolution de la température durant les étapes de chauffage et d'extraction de l'essence aromatique du citronnier «Eurêka ». Cette température est initialement voisine de la température ambiante et augmente au fur et à mesure pour atteindre $100^{\circ} \mathrm{C}$, température d'ébullition de l'eau.

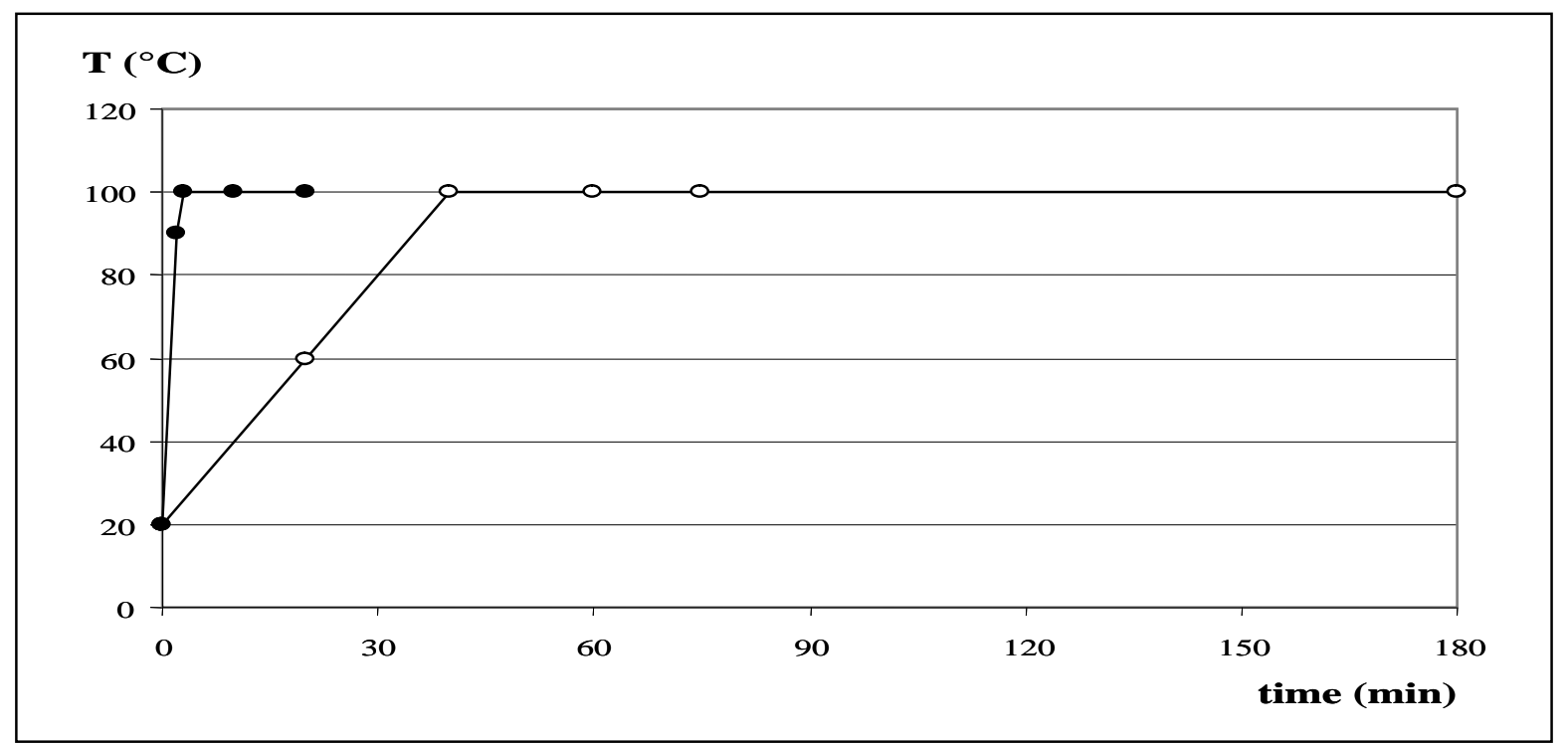

Fig.1. Evolution de la température au cours de l'extraction de l'essence aromatique Eurêka

$$
\begin{aligned}
& \text { - par ESSAM (•) } \\
& \text { - par HD (o) }
\end{aligned}
$$

Pour les essences obtenues par expression à froid, l'utilisation de grandes quantités d'eau, nécessaires à l'entraînement de l'essence et à son non réabsorption, a une influence défavorable. En effet, l'essence se trouve alors sous l'aspect de fines gouttelettes répandues dans une phase aqueuse. L'action de l'eau peut induire un effet de solubilisation des molécules hydrophiles souvent très odorantes, l'hydrolyse de certains esters odorants (acétate de linalyle) et l'activation de certaines réactions biochimiques. 


\subsection{Composition des essences aromatiques du citron « Eurêka » obtenues par ESSAM, $\mathrm{HD}$ et $\mathrm{CP}$}

Les essences terpéniques récupérées par les différents procédés on été analysées par chromatographie en phase gazeuse (GC) seule et par couplage de celle-ci à la spectrométrie de masse (GC/MS) en utilisant deux colonnes capillaires l'une polaire (Stabilwax) et l'autre apolaire (HP5 MS). Les conditions opératoires sont détaillées dans la partie expérimentale. Le Tableau 2 regroupe la composition qualitative et semi-quantitative des essences aromatiques extraites par les trois méthodes: ESSAM, CP et HD. L'huile essentielle du citronnier « eurêka », qu'elle soit hydrodistillée (48 composés) ou extraite par CP (45 composés) est constituée par un nombre d'éléments terpéniques aromatiques pratiquement égal. Ce phénomène est différent dans le cas d'une essence aromatique issue de l'ESSAM dont le nombre de constituants passe à 57. Le limonène est incontestablement le composé le plus majoritaire des distillats aromatiques de l'eurêka quelle que soit la méthode d'extraction à raison respectivement de $75,68 \%, 72,9 \%$ et $69,65 \%$ dans l'huile essentielle issue d'une CP, HD et d'une ESSAM. Cinq composés seulement sont présents avec une teneur notable : l' $\alpha$-pinène ( $1 \%$ en ESSAM, $1,34 \%$ en HD et $1,31 \%$ en CP), le $\beta$-pinène $(6,61 \%$ en ESSAM, $8,58 \%$ en HD et $8,7 \%$ en CP), le $\beta$-myrcène (1,09\% en ESSAM, $1,57 \%$ en HD et $1,62 \%$ en $\mathrm{CP})$, le $\gamma$-terpinène $(6,88 \%$ en ESSAM, $7,77 \%$ en $\mathrm{HD}$ et $7,19 \%$ en $\mathrm{CP})$ et le géranial $(0,94 \%$ en ESSAM, 1,22\% en HD et 1,05\% en CP). Selon la technique d'extraction utilisée la Figure 2 illustre les proportions de la fraction oxygénée, la plus aromatique et donc la plus valorisable au niveau olfactif de l'huile essentielle. L'analyse des résultats montre que l'essence terpénique obtenue par ESSAM est la plus riche en composés oxygénés $(6,03 \%)$ suivie de l'HD $(5,51 \%)$ et de la CP $(3,35 \%)$.

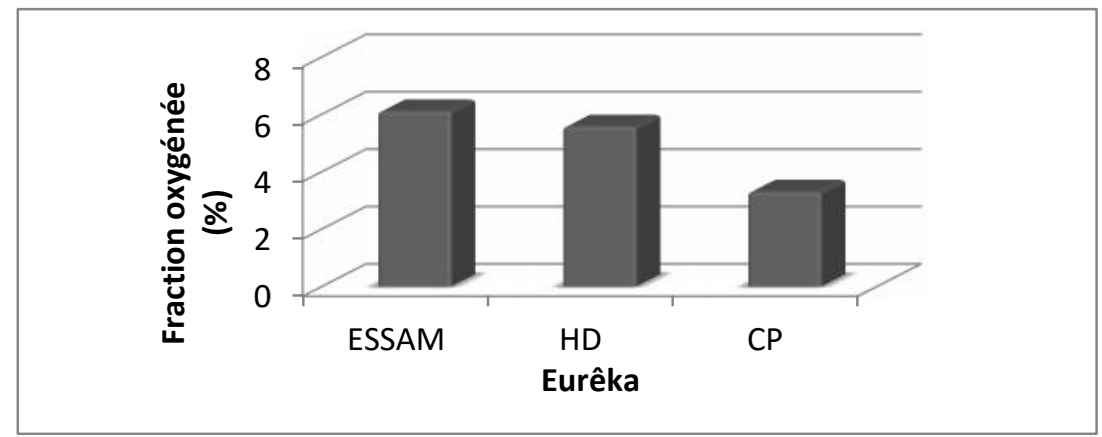

Fig.2. Proportion de la fraction oxygénée au sein de l'essence aromatique du citron Eurêka après extraction selon trois méthodes. 
Tableau 2. Composition de l'huile essentielle de l'Eurêka obtenue par ESSAM, HD et CP.

\begin{tabular}{|c|c|c|c|c|c|c|c|}
\hline $\mathrm{N}^{\circ}$ & composés & $\begin{array}{c}\text { RI } \\
\text { apolaire }\end{array}$ & $\begin{array}{c}\text { RI } \\
\text { polaire }\end{array}$ & ESSAM $\%$ & $\mathrm{HD} \%$ & $\mathrm{CP} \%$ & $\begin{array}{c}\text { méthode } \\
\text { d'identification }\end{array}$ \\
\hline & Monoterpènes & & & 86,03 & 93,23 & 95,37 & \\
\hline 1 & Thujène<Alpha-> & 920 & 1036 & 0,18 & 0,26 & 0,28 & $\mathrm{CG}, \mathrm{CG}-\mathrm{SM}$ \\
\hline 2 & Pinène<Alpha-> & 926 & 1023 & 1 & 1,34 & 1,31 & CG,CG-SM \\
\hline 3 & Camphène & 942 & 1103 & 0,04 & 0,04 & 0,03 & CG,CG-SM \\
\hline 4 & Pinène<Béta-> & 974 & 1109 & 6,61 & 8,58 & 8,7 & $\mathrm{CG}, \mathrm{CG}-\mathrm{SM}$ \\
\hline 5 & Myrcène<Bèta-> & 988 & 1165 & 1,09 & 1,57 & 1,62 & $\mathrm{CG}, \mathrm{CG}-\mathrm{SM}$ \\
\hline 6 & Phellandrène $<$ Alpha- $>$ & 1001 & 1268 & 0,02 & 0,05 & 0,03 & $\mathrm{CG}, \mathrm{CG}-\mathrm{SM}$ \\
\hline 7 & Terpinène<Alpha-> & 1020 & 1083 & 0,15 & 0,21 & 0,14 & $\mathrm{CG}, \mathrm{CG}-\mathrm{SM}$ \\
\hline 8 & Limonène & 1030 & 1206 & 69,65 & 72,9 & 75,68 & CG,CG-SM \\
\hline 9 & Carène<Delta-3-> & 1101 & 1290 & 0,07 & 0,09 & 0,07 & $\mathrm{CG}, \mathrm{CG}-\mathrm{SM}$ \\
\hline 10 & Terpinène<Gamma-> & 1103 & 1285 & 6,88 & 7,77 & 7,19 & $\mathrm{CG}, \mathrm{CG}-\mathrm{SM}$ \\
\hline 11 & Terpinolène & 1120 & 1304 & 0,32 & 0,39 & 0,31 & $\mathrm{CG}, \mathrm{CG}-\mathrm{SM}$ \\
\hline 12 & Ocimène & 1144 & 1382 & 0,02 & 0,03 & 0,01 & $\mathrm{CG}, \mathrm{CG}-\mathrm{SM}$ \\
\hline & Monoterpènes Oxygénés & & & 3,93 & 4,53 & 2,00 & \\
\hline 13 & Sabinène hydrate<Cis-> & 1112 & - & 0,13 & - & 0,02 & $\mathrm{CG}, \mathrm{CG}-\mathrm{SM}$ \\
\hline 14 & Linalol & 1125 & 1538 & 0,19 & 0,30 & 0,11 & $\mathrm{CG}, \mathrm{CG}-\mathrm{SM}$ \\
\hline 15 & Fenchol<Endo-> & 1134 & 1574 & 0,01 & 0,02 & - & CG,CG-SM \\
\hline 16 & Menth-2-en-1-ol<Cis-Para-> & 1139 & 1552 & 0,05 & 0,03 & - & $\mathrm{CG}, \mathrm{CG}-\mathrm{SM}$ \\
\hline 17 & Limonène Oxyde<Trans-> & 1151 & 1458 & 0,03 & - & - & $\mathrm{CG}, \mathrm{CG}-\mathrm{SM}$ \\
\hline 18 & Camphre & 1158 & 1514 & 0,11 & 0,01 & - & $\mathrm{CG}, \mathrm{CG}-\mathrm{SM}$ \\
\hline 19 & Citronellal & 1167 & 1478 & 0,03 & 0,05 & 0,03 & $\mathrm{CG}, \mathrm{CG}-\mathrm{SM}$ \\
\hline 20 & Bornéol & 1176 & 1679 & 0,07 & 0,02 & - & $\mathrm{CG}, \mathrm{CG}-\mathrm{SM}$ \\
\hline 21 & Terpin-4-ol & 1191 & 1590 & 0,14 & 0,29 & 0,01 & $\mathrm{CG}, \mathrm{CG}-\mathrm{SM}$ \\
\hline 22 & Terpinèol<Alpha-> & 1203 & 1677 & 0,37 & 0,39 & 0,15 & $\mathrm{CG}, \mathrm{CG}-\mathrm{SM}$ \\
\hline 23 & Nérol n & 1237 & 1781 & 0,44 & 0,53 & 0,01 & CG,CG-SM \\
\hline 24 & Néral & 1268 & 1670 & 0,63 & 0,95 & 0,6 & $\mathrm{CG}, \mathrm{CG}-\mathrm{SM}$ \\
\hline 25 & Carvone & 1269 & 1723 & 0,14 & 0,06 & - & $\mathrm{CG}, \mathrm{CG}-\mathrm{SM}$ \\
\hline 26 & Géraniol & 1271 & 1828 & 0,59 & 0,64 & 0,01 & $\mathrm{CG}, \mathrm{CG}-\mathrm{SM}$ \\
\hline 27 & Géranial & 1284 & 1714 & 0,94 & 1,22 & 1,05 & $\mathrm{CG}, \mathrm{CG}-\mathrm{SM}$ \\
\hline 28 & Périlla alcool & 1313 & 1991 & 0,06 & 0,02 & - & CG,CG-SM \\
\hline & Sesquiterpènes & & & 1,59 & 1,15 & 1,61 & \\
\hline 29 & Elémène<Delta-> & 1339 & 1470 & 0,05 & 0,04 & 0,05 & $\mathrm{CG}, \mathrm{CG}-\mathrm{SM}$ \\
\hline 30 & Caryophyllène<E-> & 1418 & 1594 & 0,27 & 0,21 & 0,23 & $\mathrm{CG}, \mathrm{CG}-\mathrm{SM}$ \\
\hline 31 & Bergamotène $<$ Alpha-Trans- $>$ & 1437 & 1577 & 0,28 & 0,25 & 0,40 & $\mathrm{CG}, \mathrm{CG}-\mathrm{SM}$ \\
\hline 32 & Humulène<Alpha-> & 1450 & 1657 & - & 0,04 & - & $\mathrm{CG}, \mathrm{CG}-\mathrm{SM}$ \\
\hline 33 & Farnésène<(E)-Beta-> & 1453 & 1650 & 0,07 & 0,01 & 0,17 & CG,CG-SM \\
\hline 34 & Curcumène $<$ Gamma-> & 1475 & 1805 & 0,04 & 0,03 & 0,03 & CG,CG-SM \\
\hline 35 & Valencène & 1488 & 1705 & 0,06 & 0,08 & 0,02 & CG,CG-SM \\
\hline
\end{tabular}




\begin{tabular}{|c|c|c|c|c|c|c|c|}
\hline 36 & Bicyclogermacrène & 1491 & 1731 & 0,07 & 0,07 & 0,02 & CG,CG-SM \\
\hline 37 & Muurolène<Alpha-> & 1493 & 1706 & 0,01 & - & - & CG,CG-SM \\
\hline 38 & Bisabolène < (Z)-Alpha-> & 1498 & 1761 & 0,03 & 0,03 & 0,04 & CG,CG-SM \\
\hline 39 & Bisabolène(Béta-) & 1508 & 1718 & 0,44 & 0,37 & 0,58 & CG,CG-SM \\
\hline 40 & Bisabolène< (Z)-Gamma-> & 1512 & - & 0,06 & 0,02 & 0,04 & CG,CG-SM \\
\hline 41 & Cadinène $<$ Delta- $>$ & 1517 & 1746 & - & - & 0,02 & CG,CG-SM \\
\hline \multirow[t]{2}{*}{42} & Bisabolène<( E )-Gamma-> & 1527 & 1761 & 0,21 & - & 0,01 & CG,CG-SM \\
\hline & Sesquiterpènes Oxygénés & & & 0,20 & 0,04 & 0,09 & \\
\hline 43 & Caryophyllène Alcool & 1560 & - & 0,01 & - & - & CG,CG-SM \\
\hline 44 & Germacrène D-4-ol & 1567 & 2041 & 0,06 & - & 0,06 & CG,CG-SM \\
\hline 45 & Muurolol<Alpha-> & 1635 & 2178 & 0,02 & - & - & CG,CG-SM \\
\hline 46 & Cadinol<Alpha-> & 1651 & 2165 & 0,01 & 0,01 & - & CG,CG-SM \\
\hline 47 & Bisabolol<Alpha-> & 1684 & 2212 & 0,05 & 0,03 & 0,03 & CG,CG-SM \\
\hline 48 & Bisabolol<Epi-Alpha-> & 1692 & - & 0,02 & - & - & CG,CG-SM \\
\hline 49 & Farnésol<(E, E) -> & 1722 & 2341 & 0,02 & - & - & CG,CG-SM \\
\hline \multirow[t]{2}{*}{50} & Nootkatone & 1799 & 2250 & 0,01 & - & - & CG,CG-SM \\
\hline & AutresComposés Oxygénés & & & 1,90 & 0,94 & 1,26 & \\
\hline 51 & Nonanal $<\mathrm{N}->$ & 1126 & 1544 & - & - & 0,02 & CG,CG-SM \\
\hline 52 & Décanal & 1211 & 1497 & - & 0,07 & 0,01 & CG,CG-SM \\
\hline 53 & Undécanal & 1318 & 1592 & 0,08 & 0,06 & 0,01 & CG,CG-SM \\
\hline 54 & Méthyl Géraniate & 1331 & - & 0,04 & 0,03 & 0,01 & CG,CG-SM \\
\hline 55 & Citronellyl Acétate & 1361 & 1645 & 0,14 & 0,02 & 0,08 & CG,CG-SM \\
\hline 56 & Néryl Acétate & 1372 & 1706 & 0,52 & 0,48 & 0,36 & CG,CG-SM \\
\hline 57 & Géranyl Acétate & 1394 & 1742 & 0,31 & 0,27 & 0,20 & CG,CG-SM \\
\hline 58 & Géranyl N-Propionate & 1473 & 1802 & 0,1 & 0,01 & 0,02 & CG,CG-SM \\
\hline 59 & Dill Apiole & 1622 & - & 0,1 & - & - & CG,CG-SM \\
\hline 60 & Citroptène & 1980 & - & - & - & 0,55 & CG,CG-SM \\
\hline 61 & Acide Palmitique & 1981 & 2272 & 0,36 & - & - & CG,CG-SM \\
\hline \multirow[t]{3}{*}{62} & Acide Linoléique & 2144 & 2475 & 0,25 & - & - & CG,CG-SM \\
\hline & Composés Oxygénés Totaux & & & 6,03 & 5,51 & 3,35 & \\
\hline & $\begin{array}{l}\text { Composés non Oxygénés } \\
\text { Totaux }\end{array}$ & & & 87,62 & 94,38 & 96,98 & \\
\hline
\end{tabular}




\subsection{Influence du temps d'extraction sur le rendement en essence aromatique}

La durée d'extraction est théoriquement le temps fondamental à la récupération de la totalité de l'huile contenue dans la matière végétale. Or en pratique, il est laborieux de récupérer toute l'huile. Ce temps correspond alors au moment pour lequel nous n'observons plus d'huile dans le distillat. Il détermine la fin du processus. Lors de cette étude, un suivi cinétique a été réalisé sur l'extraction de l'essence aromatique par HD et ESSAM. La Figure 3 présente pour les deux techniques HD et ESSAM étudiées l'évolution du rendement en essences lors de l'extraction du citron Eurêka.

Rdt

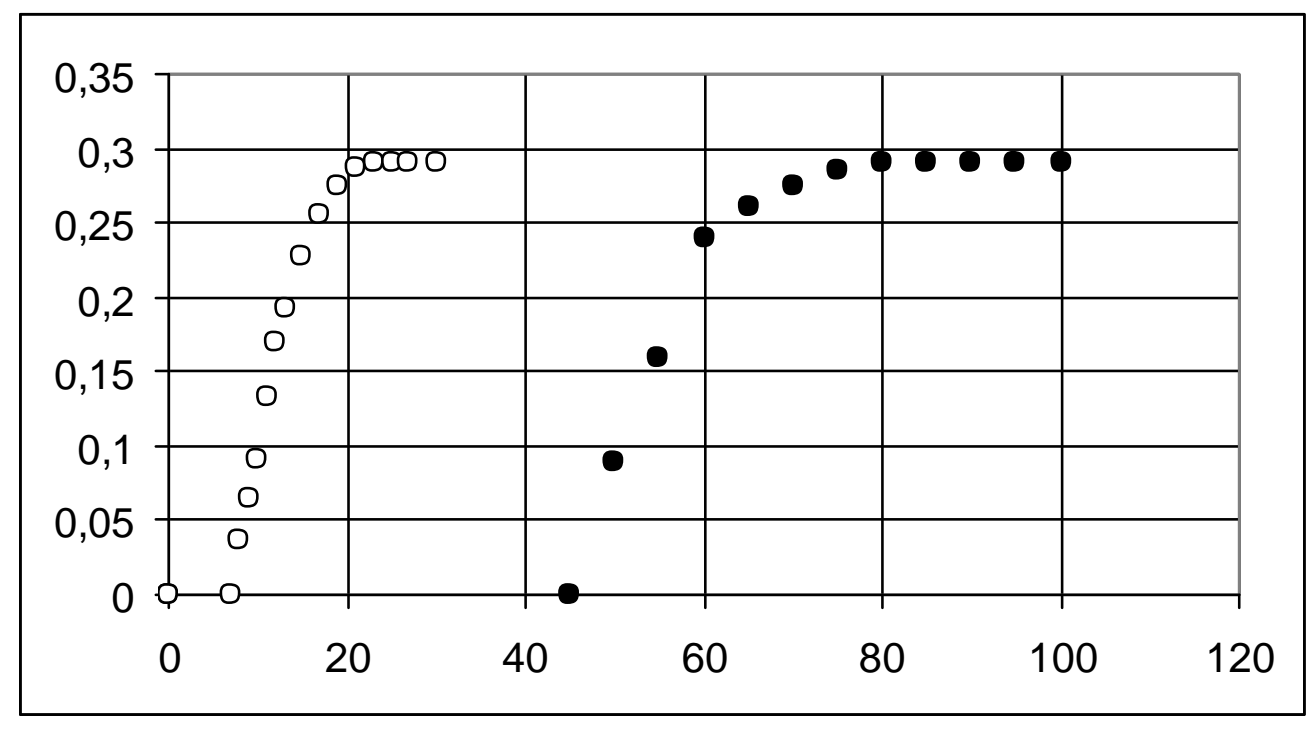

Fig. 3. Cinétique de l'extraction de l'HE d'Eurêka par :

$\mathrm{T}(\min )$

- $\operatorname{ESSAM}(0)$

$-\mathrm{HD}(\bullet)$

Cette étude cinétique montre l'existence de trois étapes :

- une première partie relative au chauffage de la matière végétale et correspondant à la montée en température au sein du réacteur, étape durant laquelle aucune extraction d'huile essentielle ne se produit.

- la seconde étape correspond à une extraction plus ou moins rapide de l'essence selon la technique d'extraction et la matrice traitée. 
- enfin, au cours de la troisième étape la courbe tend vers un second palier, qui correspond au rendement maximum possible d'être atteint dans les conditions expérimentales optimisées pour une matrice donnée.

Du fait des modalités initiales, la phase de chauffage est beaucoup plus courte pour l'ESSAM que pour l'HD. La durée d'extraction par ESSAM est relativement courte puisqu'au bout de 30 minutes nous n'observons plus de distillat. Le rendement augmente rapidement durant les 20 minutes où plus de $87 \%$ de l'huile sont extraits, son évolution devient plus lente par la suite.

En conséquence, pour atteindre un même rendement en essence aromatique, il est nécessaire de chauffer le matériel végétale seulement 20 minutes en ESSAM et plus de deux heures en HD. De cette façon la matière végétale subit moins les effets du chauffage lors d'une ESSAM. Par ailleurs, l'allure des deux courbes suggère que le processus d'extraction est régi par deux lois physiques différentes. Nous tenterons d'apporter des éléments de réponse à ces hypothèses lors de l'étude des phénomènes d'extraction.

\subsection{Influence du temps d'extraction sur la composition de l'essence aromatique :}

Afin d'évaluer l'influence du temps d'extraction sur la composition de l'essence aromatique, selon les deux procédés, des échantillons d'essence sont récupérés respectivement, à des intervalles de temps réguliers de 5, 15 et 30 minutes, après l'obtention de la première goutte d'huile essentielle.

Dans le Tableau 3 les variations de la teneur relative de quelques constituants majoritaires de l'essence, appartenant à différentes familles chimiques à savoir : le limonène, le géranial, le $\beta$-bisabolène, le néryl acétate, et le géranyl acétate sont reportées en fonction du temps. L'observation des histogrammes de la figure 4 montre que d'un point de vue qualitatif, l'huile essentielle obtenue par ESSAM est pratiquement identique à celle obtenue par hydrodistillation. Cependant des différences sont à relever concernant les teneurs des différents constituants majoritaires identifiés.

Le limonène et le géranial atteignent leurs teneurs maximales après 15 minutes d'extraction aussi bien pour l'ESSAM que l'HD. La teneur maximale du $\beta$-bisabolène est obtenue en 15 minutes pour l'HD alors qu'il faut 30 minutes pour l'ESSAM. Le néryl acétate est obtenue en 
plus grande proportion au terme de 30 minutes de traitement par ESSAM alors que 5 minutes suffisent pour atteindre sa teneur optimale par HD. Enfin le géranyl acétate est obtenu en plus grande proportion après 15 minutes de traitement par ESSAM et 30 min par HD.

Tableau 3. Evolution en fonction du temps de la teneur relative des constituants majoritaires contenus dans l'huile essentielle de la variété Eurêka

\begin{tabular}{ccccccc}
\hline & \multicolumn{2}{c}{5 min } & \multicolumn{2}{c}{$15 \mathrm{~min}$} & \multicolumn{2}{c}{$30 \mathrm{~min}$} \\
Limonène & 72.68 & 67.09 & 72.71 & 69.76 & 71.39 & 68.04 \\
Géranial & 1.67 & 2.43 & 1.64 & 2.25 & 0.94 & 1.90 \\
$\beta$-bisaboléne & 0.42 & 0.41 & 0.57 & 0.40 & 0.55 & 0.44 \\
Néryl acétate & 0.81 & 0.70 & 0.71 & 0.84 & 0.77 & 0.85 \\
Géranyl acétate & 0.38 & 0.48 & 0.35 & 0.5 & 0.41 & 0.46 \\
\hline
\end{tabular}

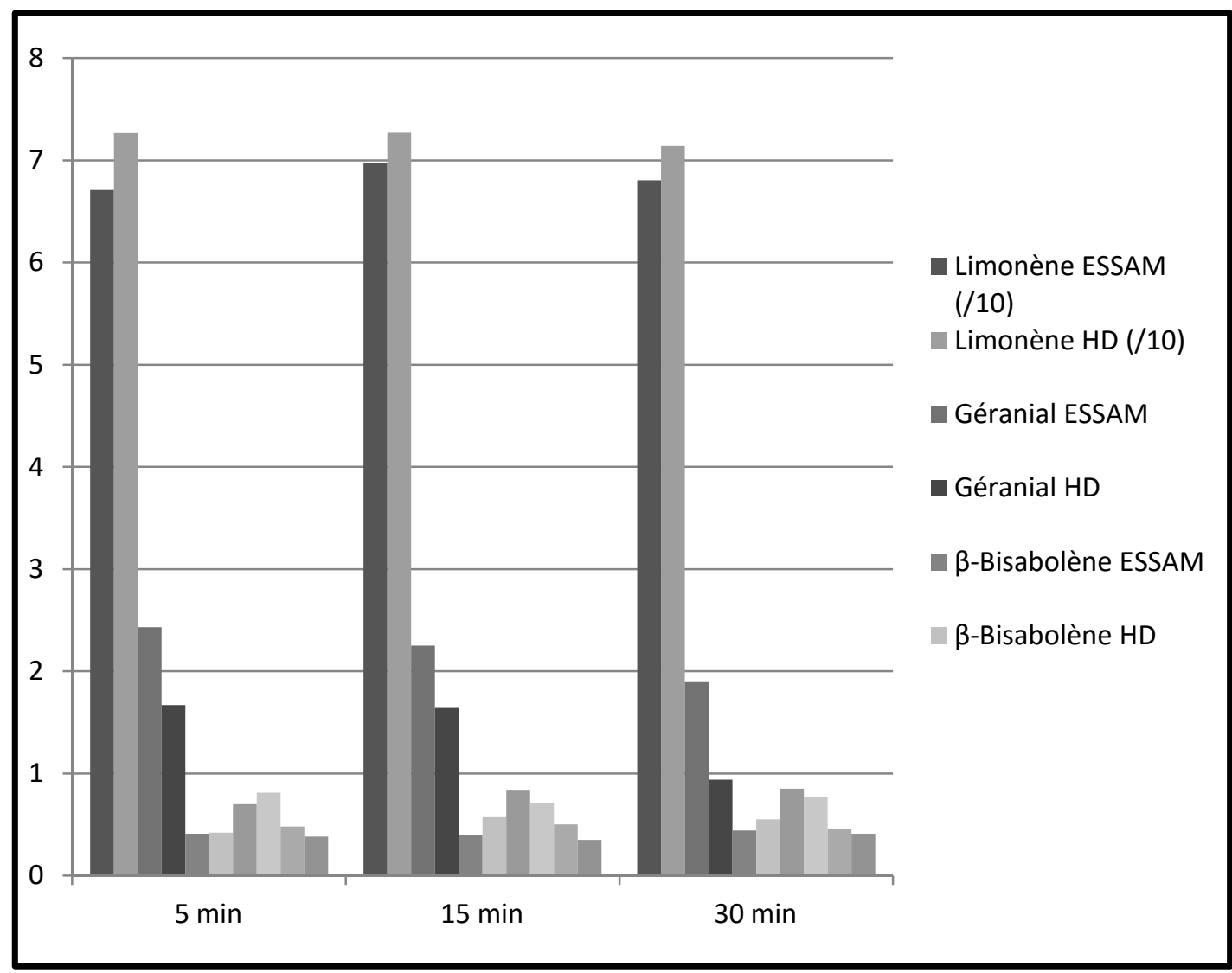

Fig.4. Evolution des concentrations de quelques constituants majoritaires contenus dans l'huile essentielle de la variété Eurêka extraite par ESSAM et HD. (/10) : la hauteur du limonène a été divisée par 10 compte tenu de sa forte teneur 


\subsection{Constantes physico-chimiques :}

Les constantes physico-chimiques des huiles aromatiques de la variété Eurêka obtenues par ESSAM, HD et CP ont été déterminées selon les normes AFNOR [4]. Les résultats des mesures de densité, d'indice de réfraction, du pouvoir rotatoire et de la valeur CD (par spectrophotométrie UV-Visible) sont regroupés dans le Tableau 4.

Tableau 4. Constantes physico-chimiques des huiles essentielles de la variété Eurêka obtenues par ESSAM, HD, et CP.

\begin{tabular}{lccc}
\hline Constantes physico- & & Eurêka & \\
chimiques & ESSAM & HD & $\mathrm{CP}$ \\
Densité & 0,834 & 0,849 & 0,856 \\
Indice de réfraction & 1,474 & 1,474 & 1,475 \\
Pouvoir rotatoire & $+64^{\circ}$ & $+62^{\circ}$ & $+69^{\circ}$ \\
\hline
\end{tabular}

Nous constatons que les densités et les indices de réfraction des huiles essentielles recueillies ont des valeurs relativement proches quel que soit son mode d'extraction. Les valeurs du pouvoir rotatoire des essences aromatiques, tout en restant du même ordre de grandeur, présentent des différences plus significatives selon leur mode d'obtention. La valeur CD déterminé par analyse spectrophotométrie dans l'ultraviolet permet un contrôle de la pureté et de l'authenticité des HE. Ces valeurs dépendent de l'équilibre naturel de trois sortes de constituants : les hydrocarbures terpéniques, le citral (Néral + géranial) et les composés non volatils.

\subsection{Etude de l'activité antimicrobienne des essences aromatiques de la variété Eurêka}

Nous avons appliqué la technique par contact direct dite «aromatogramme » pour évaluer l'activité antimicrobienne des essences obtenues par ESSAM, HD et CP. Ce test a été effectué suivant la méthode utilisée par divers auteurs (Conner et Beuchat [5], Adam et coll. [6] et Chao et coll. [7]) et en respectant les recommandations établies par le BSAC (British Society Antimicrobial Chemotherapy) développées par Andrews [8].

Les résultats de l'activité antimicrobienne des essences aromatiques obtenue par mesure des diamètres d'inhibition de la croissance des germes microbiens sont reportés dans les Tableaux 
5 (bactéries gram+), 6, (bactéries gram-) et 7 (levures).

Tableau 5. Diamètre des zones d'inhibitions $(\mathrm{mm})$ montrant l'activité antimicrobienne par diffusion par disque pour les bactéries $\mathrm{Gram}^{+}$

\begin{tabular}{|l|c|c|c|}
\hline Souches & $\begin{array}{c}\text { Staphylococcus } \\
\text { aureus } \\
\text { ATCC 6538 }\end{array}$ & $\begin{array}{c}\text { Staphylococcus } \\
\text { epidermis } \\
\text { ATCC 12228 }\end{array}$ & $\begin{array}{c}\text { Enterococcus } \\
\text { faecium } \\
\text { ATCC 6569 }\end{array}$ \\
\hline ESSAM & $12,50 \pm 1,06$ & $13 \pm 1,41$ & $20 \pm 1,76$ \\
\hline CP & $12,50 \pm 1.06$ & $11 \pm 1,53$ & $17 \pm 1,06$ \\
\hline HD & $12 \pm 0,35$ & $17 \pm 1,25$ & $20 \pm 1,41$ \\
\hline
\end{tabular}

Tableau 6. Diamètre des zones d'inhibitions $(\mathrm{mm})$ montrant l'activité antimicrobienne par diffusion par disque pour les bactéries Gram ${ }^{-}$

\begin{tabular}{|l|c|c|c|}
\hline Souches & $\begin{array}{c}\text { Pseudomonas } \\
\text { aeruginosa }\end{array}$ & $\begin{array}{c}\text { Escherichia } \\
\text { coli }\end{array}$ & $\begin{array}{r}\text { Klebsiella } \\
\text { pnemonia }\end{array}$ \\
\hline ATCE 9027 & ATCC 4157 & ATCC 4352 \\
\hline ESSAM & $12 \pm 0,70$ & $20 \pm 1,50$ & $17 \pm 0,76$ \\
\hline CP & $11 \pm 1,04$ & $19,50 \pm 1,25$ & $16 \pm 1,25$ \\
\hline HD & $12 \pm 2,12$ & $19 \pm 1,26$ & - \\
\hline
\end{tabular}


Tableau 7. Diamètre des zones d'inhibitions $(\mathrm{mm})$ montrant l'activité antimicrobienne par diffusion par disque pour les levures

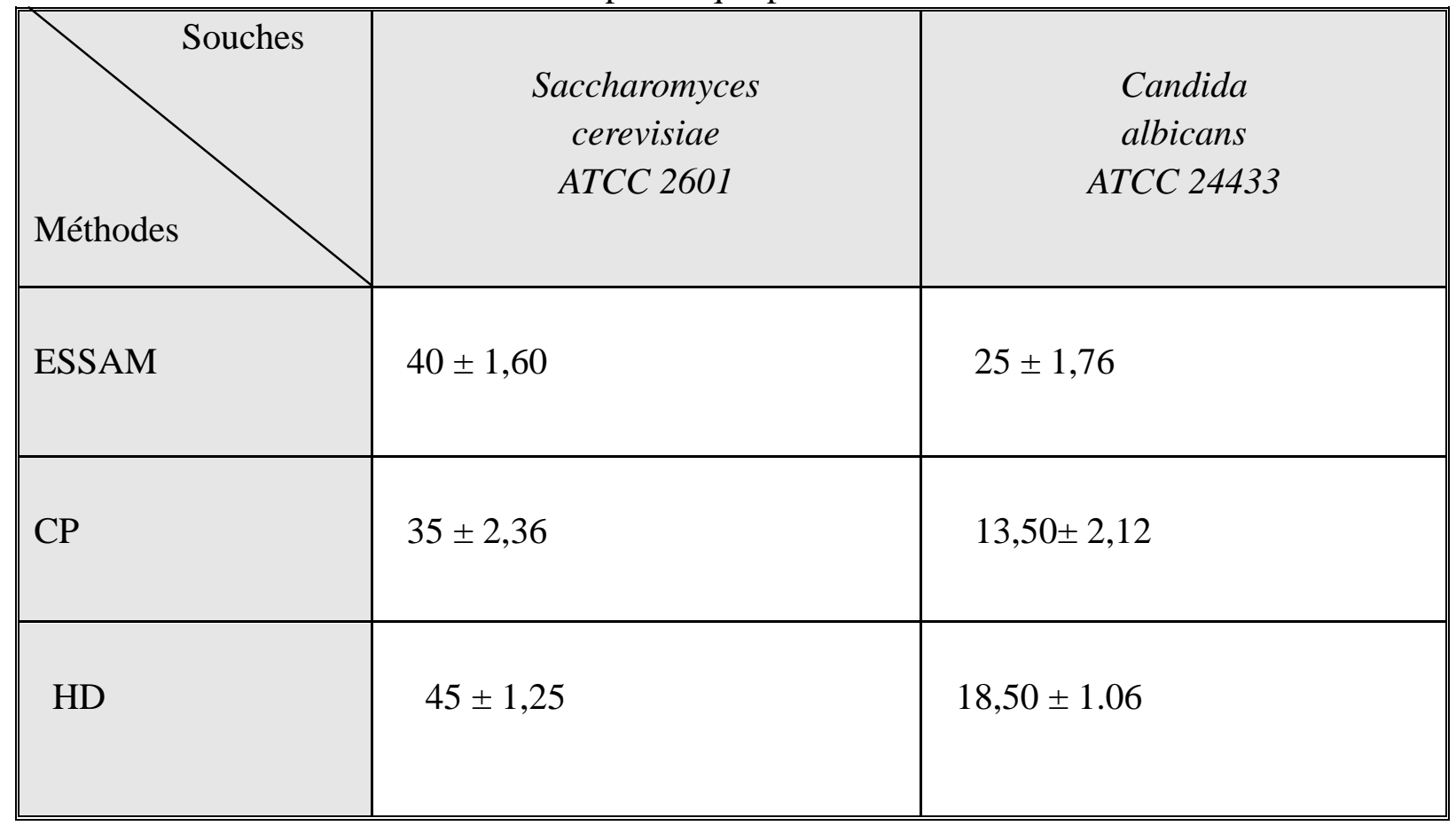

Le diamètre du disque en papier filtre $(6 \mathrm{~mm})$ est inclue. Aucune inhibition $(\leq 6 \mathrm{~mm}$ de diamètre).

Les résultats obtenus sont en général en concordance avec les études rapportées dans la littérature. Tous les isolats bactériens ont exhibé un certain degré de sensibilité aux essences aromatiques utilisées. Une échelle de mesure de l'activité antimicrobienne des essences fut émise d'une part par Ela et coll. [9] et Meena et Sethi [10]. Les diamètres des zones d'inhibition (DZI) de la croissance microbienne étaient classés en 04 classes :

- Fortement inhibitrice lorsque : $\varnothing \geq 28 \mathrm{~mm}$ de DZI ;

- Modérément inhibitrice lorsque : $28 \mathrm{~mm}>\varnothing>16 \mathrm{~mm}$ de DZI ;

- Légèrement inhibitrice lorsque : $16 \mathrm{~mm}>\varnothing>10 \mathrm{~mm}$ de DZI ;

- Non inhibitrice lorsque : $\varnothing<10 \mathrm{~mm}$ de DZI.

L'huile essentielle obtenue par $\mathrm{CP}$ a montré en général, une action légèrement inhibitrice de la croissance des $\mathrm{Gram}^{+}$. Cette action diffère légèrement des deux autres techniques d'extraction où elle devient parfois modérément inhibitrice en particulier au contact de $E$. faecium. Au contact des Gram, l'huile obtenue par les trois méthodes d'extraction conserve son action légèrement inhibitrice envers deux souches d'entre elles, mais son action change pour devenir modérément inhibitrice au contact de E. coli.

Chez les levures, nous remarquons la présence d'une action fortement inhibitrice de la 
croissance de S. cerevisiae pour les trois techniques d'extraction comme le montre la Figure II.8. L'huile obtenue par ESSAM, enregistre sa plus grande valeur $\quad(\mathrm{d}=25 \mathrm{~mm}$ de diamètre $)$ au contact de C. albicans, mais elle devient légèrement inhibitrice dans les deux méthodes d'extraction (CP et HD) .

Dans leurs travaux, Deans et coll. [11-13], proposent que la susceptibilité des bactéries envers les essences végétales ne semble avoir qu'une petite influence sur l'inhibition de la croissance microbienne. Dans cette étude, les essences testées sur les différentes germes bactériens à Gram + et à Gram - ont présenté une action variable. Ceci est expliqué par Chao et al. [7], du fait que les bactéries Gram négatif sont dotées d'une couche de peptidoglycane coincé entre la membrane plasmique et une assise externe constituée de lipopolysaccharids et de protéines. Cette structure peut empêcher la prise d'huile ou protéger la couche peptidoglycane vis-à-vis des huiles. La membrane externe de lipopolysaccharids (LPS) des bactéries gram négatif constitue une barrière à la perméabilité des substances hydrophobes, qui en entrant empêchaient la croissance des bactéries Gram négatif.

Dans le cas précis des bactéries $\left(\mathrm{Gram}^{+}\right)$, la couche peptidoglycane se situe à l'extérieur, permettant ainsi à ces bactéries d'être plus disponibles à entrer en contact avec les huiles. Nous remarquons également, que parmi les souches testées $P$. aeruginosa $\left(\mathrm{Gram}^{-}\right)$est la bactérie la plus résistante à l'action de ces HE. Ces résultats sont en accord avec les études de Kivanc et Akgul [14], Tasson et Nychas [15], Chao et coll. [7], Mann et coll. [16], Inouye et coll. [17], Farag et coll. [18], qui rapportent tous que la faible susceptibilité de P. aeruginosa à l'action des huiles essentielles peut être due à sa membrane externe particulière et à sa capacité de métaboliser un éventail de composés organiques. Conner et Beuchat [5], ont suggéré que le mode potentiel de l'action des essences aromatiques contre les levures pourrait être dû à l'affaiblissement des processus enzymatiques impliqués dans la production énergétique et la synthèse des composantes structurales.

\subsection{Analyse sensorielle des essences aromatiques de la variété Eurêka}

Chaque fragrance dépend des perceptions olfactives successives de nuances citronnées, florales puis fruitées. Cette combinaison commune aux essences de Citrus permet de les regrouper en une classe de senteurs : Hespéridées. Toutes les essences de Citrus possèdent une nuance citronnée. Ce caractère commun est dû à la présence des hydrocarbures 
terpéniques tels que le pinène, le myrcène ou le limonène qui peuvent représenter plus de $90 \%$ de la composition de l'huile essentielle. Cette nuance est renforcée par la présence du linalol et de l'acétate de linalyle. Une nuance florale distingue particulièrement l'huile essentielle de néroli et de petit-grain avec la présence d'alcools tels que le terpinéol, le nérol et le géraniol. Une nuance fruitée soutenant les deux précédentes traduit la présence d'esters et d'anthranilate de méthyle. Elle est particulièrement marquée dans les essences de mandarine et renforcée dans l'essence de citron par des aldéhydes.

\subsubsection{Signes distinctifs de chaque essence de Citrus}

Les essences d'agrumes accompagnées des essences de néroli et de petit-grain constituent le complexe «agrume» dont l'odeur générale caractéristique est qualifiée de «fraîche ». Cependant, chacune de ces essences possède des caractéristiques odorantes particulières, motivant leur emploi dans différents types de parfums ou de produits cosmétiques [19].

- Essence de citron : son parfum est frais, acide et comprend un accent fruité et vert enveloppé d'une note d'amertume. La composante graisseuse aldéhydique lui confère un «rayonnement » supplémentaire. La durée de ténacité de l'odeur globale est de 10 heures environ, bien que la note citronnée typique se dissipe rapidement.

- Essence d'orange douce : son odeur aromatique et fruitée lui confère une fraîcheur douce peu prononcée à caractère «mou».

- Essence d'orange amère : moins fruitée que la précédente, on peut qualifier sa fragrance de tonique, fraîche, acide, citronnée. Sa puissance est surtout due à la présence « vigoureuse » de la composante aldéhydique.

- Essence de mandarine : des notes fraîches, douces et aromatiques, mélangées à des nuances « vertes », confèrent à l'ensemble du parfum une extrême finesse en même temps qu'une grande intensité.

- Essence de lime distillée : les senteurs terpéniques, fougueuses, acides de cette essence sont fort aromatiques et rappellent l'odeur fraîche de carotte. Les éléments constitutifs caractéristiques sont très légers, cette volatilité ayant pour effet d'atténuer la sensation odorante en quelques minutes.

- Essence de lime pressée à froid : possédant moins de terpènes que l'essence distillée, elle retrouve un caractère citronné plus typique et plus tenace. 
- Essence de néroli : cette précieuse essence de fleur d'oranger, dont le nom a pour origine celui d'une princesse italienne du $16^{\text {ème }}$ siècle, est caractérisée par son odeur fraîche, verte, florale, énivrante. La note de «queue », légère et herbacée, est dominée par une note de «tête » lourde et fleurie rappelant l'odeur du jasmin. L'essence de néroli est un élément constitutif essentiel de toute eau de Cologne de grande classe.

- Essence de petit-grain : cette essence fut initialement extraite de très petits fruits de la taille d'une cerise, les « orangettes » à petites graines allongées, d'où le nom de cette huile essentielle. Ses qualités odorantes ressemblent à celles de l'essence de néroli, sans en posséder la composante fleurie. L'impression dominante semble être plus herbacée et plus tenace.

- Essence de pamplemousse : son odeur, très éloignée du caractère typique des essences de Citrus à cause de son amertume fort prononcée, est peu utilisée en parfumerie.

- Essence de bergamote: son parfum est très complexe. Son extraordinaire fraîcheur résulte de la réunion de nuances herbacées, vertes, fruitées, amères, fleuries, avec un complément de notes douces rappelant l'odeur du foin coupé. Elle est indispensable dans la plupart des compositions de parfumerie.

\subsubsection{Classification des principaux constituants en fonction de leur odeur}

Un parfum est rarement composé uniquement d'essences naturelles entières. Souvent, une ou plusieurs huiles essentielles sont accompagnées de certains de leurs composés, isolés, et destinés par leur odeur caractéristique à renforcer ou atténuer de façon sélective certaines nuances de la composition.

On peut classer les principaux constituants des huiles essentielles de Citrus selon le type d'odeur qu'ils possèdent. Les trois grands groupes déterminant respectivement les notes citronnées, florales et fruitées, sont composés de la façon suivante :

- Nuance citronnée : elle est essentiellement apportée par les hydrocarbures terpéniques et en particulier par l' $\alpha$-pinène, le $\beta$-pinène, le myrcène, le limonène et surtout l'ocimène. Ce dernier possède une note très fraîche subtilement nuancée de « vert ». Quand on sait que ce groupe de dérivés représente, selon les espèces, de $95 \%$ à $40 \%$ de l'essence totale, on comprend d'où provient l'éclatante fraîcheur citronnée caractérisant toutes ces essences. Les absolues et concrètes, avec seulement $6 \%$ de 
dérivés terpéniques, ont une odeur moins typique. Le linalol et l'acétate de linalyle se classent également dans la catégorie des odeurs citronnées. Egalement présents à des taux très appréciables dans les essences de Citrus, et en particulier dans l'essence de bergamote et de néroli, ils contribuent à soutenir la fraîcheur citronnée ou à la maintenir dans les essences déterpénées.

- Nuance florale: elle est produite par les alcools autres que le linalol, tels que l' $\alpha$-terpinéol, le citronellol, le nérol, le géraniol, le nérolidol, et le farnésol. La plupart des essences d'agrumes contiennent un pourcentage relativement modeste de ces dérivés. Dans le parfum de ces huiles essentielles, la note florale sera donc secondaire à la nuance citronnée. L'essence de néroli contient 20\% d'alcools. Dans sa fragrance, caractérisée par deux composantes, l'une fraîche et citronnée, l'autre fleurie et rappelant le jasmin, le pourcentage élevé d'alcools est responsable de la deuxième nuance si appréciée.

- Nuance fruitée : ce sont les esters tels que l'acétate de citronellyle, de linalyle, de néryl et l'anthranilate de méthyle qui sont responsables de cette nuance destinée à soutenir et à modifier la note fraîche et citronnée. L'essence de bergamote, avec 30,5\% de ces esters, possède une odeur fruitée très marquée, autant que la nuance fraîche. De même, dans l'essence de néroli, elle contribue à accentuer la ressemblance avec l'odeur du jasmin.

\subsubsection{Résultats de l'analyse sensorielle des essences aromatiques par un panel}

L'arôme d'une denrée alimentaire demeure une propriété subjective, associative et multidimensionnelle déterminée par différents facteurs organoleptiques exposant les perceptions distinguées par un expert dégustateur au niveau de la sphère bucal et nasal et rétronasal (descripteurs liés à l'arrière-goût). Son évaluation repose sur les tests de l'analyse sensorielle réalisée par un large éventail d'experts. Par ailleurs, l'étude organoleptique et sensorielle constitue une immense source de renseignements importants qui projettent une image sur les aspirations et les souahits des consommateurs.

L'objectif de cette partie est de définir et spécifier la fragrance de l'essence aromatique de la variété «Eurêka » obtenue par ESSAM, par HD et par CP. En se basant sur plusieurs d'attributs sensoriels et afin d'évaluer les fluctuations de cette propriété sensorielle [4] le 
principal objectif de ce travail est de préciser la flaveur de l'essence aromatique de la variété «Eurêka » obtenue par ces trois méthodes d'extraction. L'analyse sensorielle des huiles essentielles a été effectuée par un groupe de 12 candidats $(5$ femmes et 7 hommes âgés de 30 à 38 ans), chercheurs au sein du Laboratoire d'Analyse Organique Fonctionnelle de la Faculté de Chimie (USTHB). La flaveur des essences aromatiques appartenant au genre Citrus se caractérise par huit attributs sensoriels, à savoir: "fleuri", “fruité", “frais ", "vert ", " herbacé ", " citronné" " sucré " et " terreux " [20]. Chacun de ces attributs a été côté sur une échelle de 10 points. L'échelle était munie de deux bornes extrêmes : 0 (absence) et 10 (très fort). La Figure 5 montre les résultats de l'évaluation sensorielle des trois échantillons analysés et permet d'observer le degré de variation de chaque attribut sensoriel.

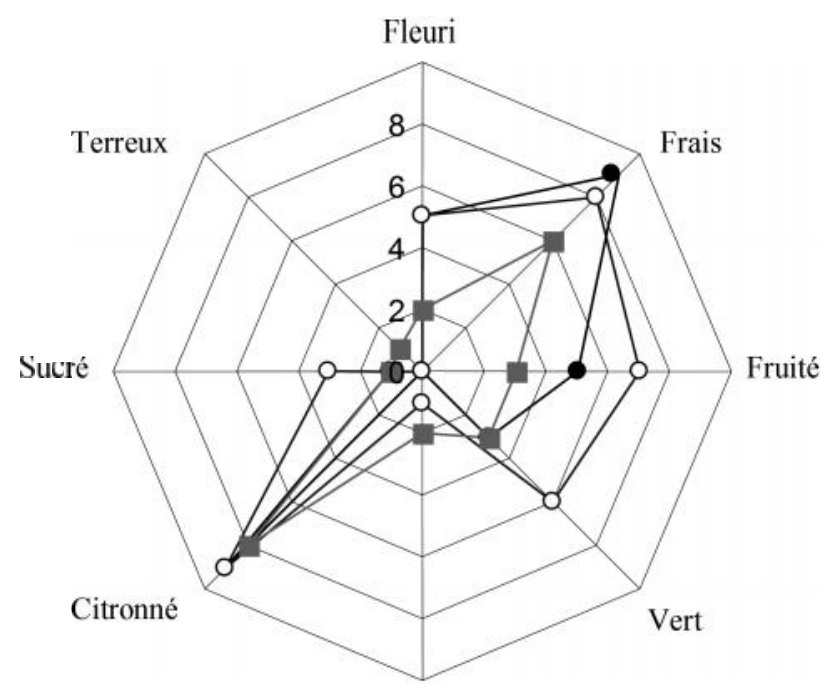

Herbacé

Fig.5. Analyse sensorielle réalise par un panel naïf sur l'HE du citron Eurêka obtenu selon 3 modes d'extraction.

$-\operatorname{ESSAM}(0)$

- CP (•)

- HD ( - )

Le taux de variation des notes accordées aux attributs " herbacé ", " sucré " et " terreux " par le panel naïf (le sujet «naïf » est une personne ne répondant à aucun critère particulier) a été le plus faible. Pour les attributs "fleuri", "fruité " et "vert", les notes moyennes obtenues ont été respectivement de 4,2, 5,2 et 4,6. Aucun échantillon n'a obtenu une note moyenne supérieure à 6. Selon ces attributs, la qualité olfactive des échantillons se situe entre une 
qualité intermédiaire (correspondant à des notes autour de 5.0) et bonne (correspondant à des notes supérieures à 6.0). Dans le cas des attributs "frais" et "citronné", la note maximale obtenue est inférieure (respectivement 7,9 et 9) à la note optimale de 10. D'une manière générale, les échantillons analysés n’ont pas présenté de défauts sensoriels particuliers. En ce qui concerne les attributs "frais "et " citronné" nous observons que les notes accordées aux échantillons obtenues par CP et ESSAM, ont été, les plus élevées dans la grande majorité des cas.

\section{MATÉRIEL ET MÉTHODES}

\subsection{Matériel végétal}

La variété d'Agrume Eurêka a été récoltée en période des mois (Mars- Avril) à la station expérimentale de Boufarik.

\subsection{Description expérimentale des trois techniques d'extraction des huiles essentielles}

\subsubsection{Conduite de l'extraction sans solvant assistée par micro-ondes}

Pour les variétés d'agrumes étudiées, le protocole expérimental est identique : 250g d'écorces râpées fraîches à l'aide d'un robot électrique sont introduites, sans ajout d'eau ni de solvant organique, dans un réacteur de type ballon d'une contenance de $500 \mathrm{~mL}$ placé dans la cavité multimode du four micro-ondes présenté dans la Figure 6.

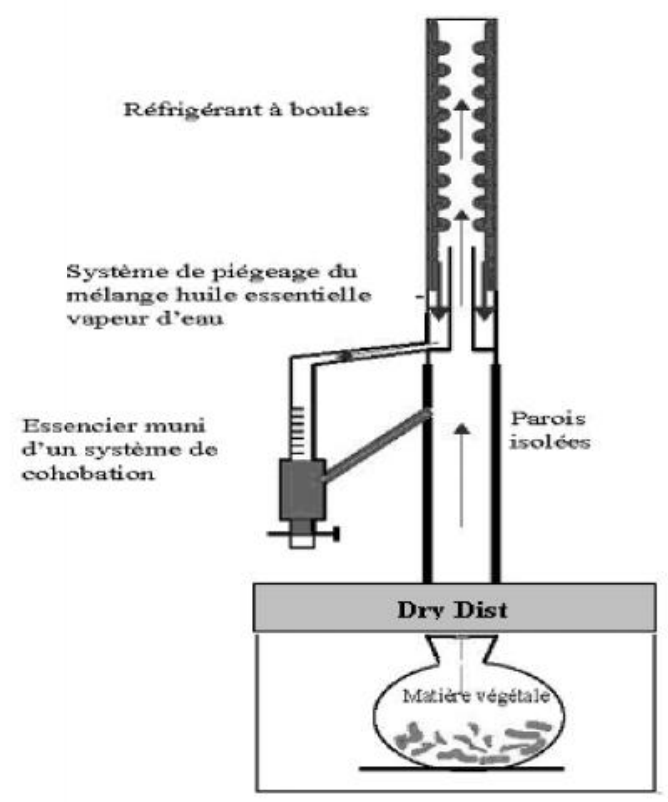

Fig.6. Schéma du montage de l'extraction sans solvant assistée par micro-ondes. 
La durée de l'extraction sans solvant assistée par micro-ondes a été fixée après les observations de la cinétique d'extraction de l'huile essentielle. Il est apparu qu'après trente minutes d'extraction, l'huile essentielle est pratiquement extraite et le flavedo vidé de ses essences. La durée totale d'une extraction sans solvant assistée par micro-ondes a donc été fixée à trente minutes comprenant l'étape de chauffage comme l'indique le Tableau 8.

Grâce au système de cohobation, le taux d'humidité au sein du ballon reste constant tout au long de l'extraction. La température initiale au sein du réacteur est voisine de la température ambiante du laboratoire soit $20^{\circ} \mathrm{C}$. Par la suite, grâce au chauffage, la température de la matrice augmente jusqu'à atteindre la température d'ébullition de l'eau $100^{\circ} \mathrm{C}$. Les expériences d'extraction sans solvant assistée par micro-ondes menées lors de ce travail sont exclusivement réalisées à pression atmosphérique. L'huile essentielle obtenue est séparée de l'eau par simple décantation. Aucun solvant organique n'est utilisé au cours de ce protocole.

L'huile essentielle est au préalable placée sur desséchant de type sulfate de sodium $\left(\mathrm{Na}_{2} \mathrm{SO}_{4}\right)$, afin d'éliminer toute trace éventuelle d'eau, puis pesée afin de calculer le rendement de l'extraction par rapport à la masse du fruit entier. Les huiles essentielles sont conservées au réfrigérateur à l'abri de la lumière et à une température de $4^{\circ} \mathrm{C}$.

Tableau 8. Conditions opératoires utilisées lors de l'extraction sans solvant assistée par micro-ondes.

\begin{tabular}{lc}
\hline Masse végétale fraîche (g) & 250 \\
Pourcentage d'humidité (\%) & 95 \\
Puissance MO maximale (W) & 1000 \\
Temps de chauffe (min) & 2,30 \\
Durée totale de l'extraction (min) & 30 \\
\hline
\end{tabular}

\subsubsection{Conduite de l'hydrodistillation}

L'extraction par hydrodistillation a été réalisée par un appareil de Clevenger modifié [21] à pression atmosphérique. Le schéma du montage utilisé est présenté dans la Figure 7. Afin de mettre en place un protocole applicable aux variétés choisies et d'optimiser les rendements de 
l'extraction tout en conservant la qualité de l'huile essentielle, plusieurs expériences préliminaires ont été menées. La charge de matière végétale traitée, la durée de l'hydrodistillation, ainsi que la quantité d'eau à utiliser sont les paramètres qui ont été optimisés au fil des expériences dans le but de trouver le meilleur compromis.

Pratiquement, pour chaque variété étudiée, $250 \mathrm{~g}$ d'écorces râpées et fraiche sont introduits dans le ballon, accompagnés de 1 litre d'eau distillée, puis chauffés pendant 3 heures après obtention de la première goutte d'huile essentielle. Grâce au système de cohobation, la quantité d'eau au sein du ballon est quasiment la même tout au long de la distillation. L'huile obtenue est séparée de l'eau par simple décantation. Aucun solvant organique n'est utilisé au cours de ce protocole. L'huile essentielle est au préalable placée sur desséchant de type sulfate de sodium, afin d'éliminer toute trace éventuelle d'eau, puis est pesée afin de calculer le rendement de l'extraction par rapport à la masse du fruit entier. Les huiles sont conservées au réfrigérateur à l'abri de la lumière et à une température de $4^{\circ} \mathrm{C}$.

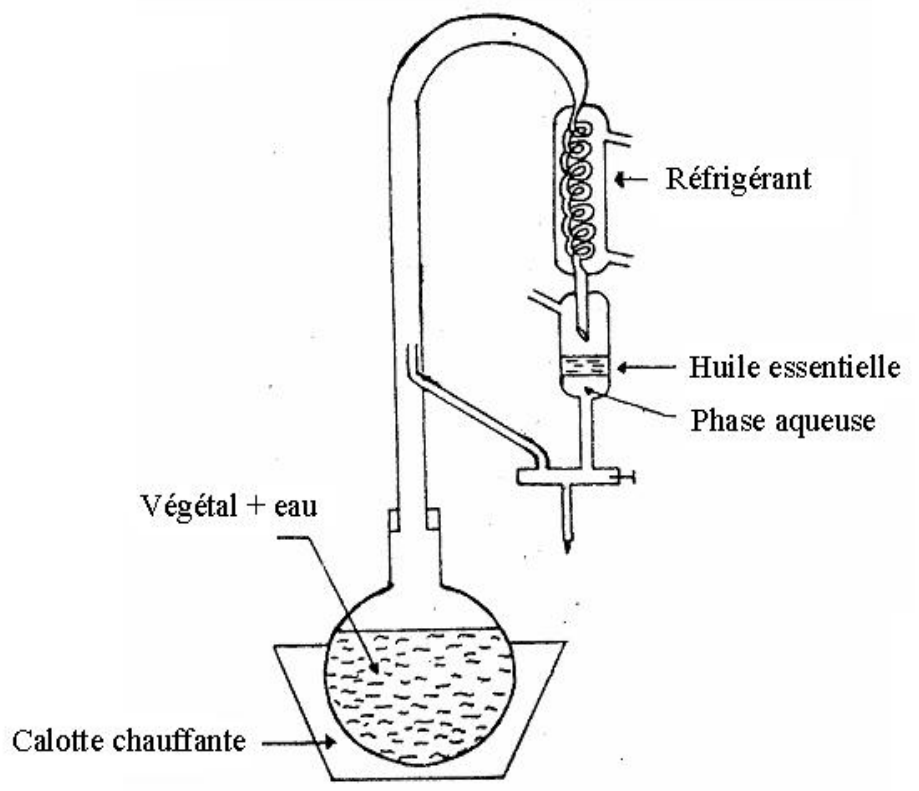

Fig.7. Schéma du montage d'hydrodistillation sur un appareil de Clevenger modifié. 


\subsubsection{Conduite de l'expression à froid}

Les fruits sont lavés à l'eau pour éviter une éventuelle contamination. Les agrumes provenant d'une plantation peuvent transporter jusqu'à 500000 micro-organismes par $\mathrm{cm}^{2}$ [22]. Les huiles essentielles d'écorces réparties dans les cellules oléifères sont obtenues par expression à froid à l'aide d'un appareil d'extraction semi industriel (BREVET SCHAUB). Chaque fruit préalablement pesé et lavé est placé dans l'appareil d'extraction qui le fait tourner sur lui-même. Une aiguille racle le péricarpe afin de percer les poches contenant les essences. Les huiles essentielles sont alors recueillie grâce à un filet d'eau, centrifugée pour enlever les matières solides et pectines puis desséchée par du sulfate de sodium afin d'éliminer toute trace éventuelle d'eau. L'essence recueillie est alors pesée afin de calculer le rendement de l'extraction par rapport à la masse du fruit entier. Les huiles sont conservées au réfrigérateur à l'abri de la lumière et à une température de $4^{\circ} \mathrm{C}$.

4. ANALYSE PAR CHROMATOGRAPHIE EN PHASE GAZEUSE (CG) ET CHROMATOGRAPHIE EN PHASE GAZEUSE COUPLEE A LA SPECTROMETRIE DE MASSE (CG/SM)

Les huiles essentielles récupérées par les trois procédés on été analysées par chromatographie en phase gazeuse seule sur appareil de marque Hewlett Packard 6890 et par couplage de celle-ci à la spectrométrie de masse (appareil Hewlett Packard 5973A). Deux colonnes capillaires, l'une polaire (Stabilwax) et l'autre apolaire (HP5 MS), ont été utilisées.

La préparation de la table des n-alcanes pour la mesure des indices de Kovats des composées identifiés dans les huiles essentielles a été faite comme suit : Solution des n-alcanes de $\mathrm{C}_{8}$ à $\mathrm{C}_{26}$ (origine: Aldrich et Fluka Chemicals) à $5 \%$ dans le pentane. Soit $0,1 \mathrm{~g}$ de chaque alcane dans $20 \mathrm{ml}$ de pentane, conservé au réfrigérateur. L'identification des composés a été effectuée par comparaison de leurs indices de rétention (indices de Kovats) et des spectres de masse ions-fragments caractéristiques obtenus expérimentalement à ceux cités dans la littérature [23] et/ ou inventoriés dans les banques de librairies spectrales (Wiley7, Nist 2002).

\section{DETERMINATION DES MESURES DES CONSTANTES PHYSICO-CHIMIQUES}

\subsection{Mesure de la densité selon la norme NF T 75-111}


Elle est effectuée à l'aide d'un pycnomètre de volume $1 \mathrm{ml}$ à la température de $20^{\circ} \mathrm{C}$

\subsection{Mesure de l'indice de réfraction selon la norme NF T 75-112}

A l'aide d'un réfractomètre de type Bellinghame permettant la lecture directe des indices de réfraction situés entre 1,3000 et 1,7000 avec une précision de $\pm 0,0002$.

Mode opératoire :

- régler le réfractomètre en mesurant les indices de réfraction des produits étalons (eau distillée, d'indice de réfraction 1,3330 à $20^{\circ} \mathrm{C}$ ).

- vérifier que le réfractomètre est maintenu à la température à laquelle les lectures doivent être effectuées, la température de référence étant de $20^{\circ} \mathrm{C}$.

- placer l'échantillon pour essai dans le réfractomètre, attendre que la température soit stable, puis effectuer la mesure.

\subsection{Mesure du pouvoir rotatoire : NF $\mathrm{T} 75-113$}

A l'aide d'un polarimètre de type JASCO 1010 (réglé de façon à donner $0^{\circ}$ et $180^{\circ}$ avec l'eau).

- source lumineuse (lampe à vapeur de sodium), permettant d'obtenir une lumière de longueur d'onde $589,3 \mathrm{~nm} \pm 0,3 \mathrm{~nm}$.

- tube d'observation, de $100 \mathrm{~mm} \pm 0,5 \mathrm{~mm}$ de longueur.

Mode opératoire :

- concentration en essence d'écorces : 0,25g/ $100 \mathrm{ml}$ d'éthanol.

- remplir le tube avec l'échantillon pour essai, en s'assurant qu'il ne reste aucune bulle d'air interposée.

- placer le tube dans le polarimètre et lire l'angle de rotation de l'échantillon pour essai sur l'échelle de l'appareil.

\section{ETUDE DE L'ACTIVITE ANTIMICROBIENNE DES HUILES ESSENTIELLES DE LA VARIETE EUREKA}

Nous avons appliqué la technique par contact direct dite «aromatogramme » pour évaluer l'activité antimicrobienne des huiles essentielles obtenues par ESSAM, HD et CP. Ce test a été effectué suivant la méthode utilisée par divers auteurs (Conner et Beuchat [5], Adam et 
coll. [6] et Chao et coll. [7]) et en respectant les recommandations établies par le BSAC (British Society Antimicrobial Chemotherapy) développées par Andrews [8].

\subsection{Principe de l'aromatogramme}

Ce test est effectué par dépôt de disque stérile de cellulose de $6 \mathrm{~mm}$ de diamètre (Whatman $\mathrm{N}^{\circ} 1$ ) imprégné d'une quantité de 501 d'HE sur un milieu gélosé préalablement ensemencé avec une culture microbienne. Après incubation, la lecture des résultats se fait par mesure des diamètres des zones d'inhibition en millimètres comme le montre la figure 8.

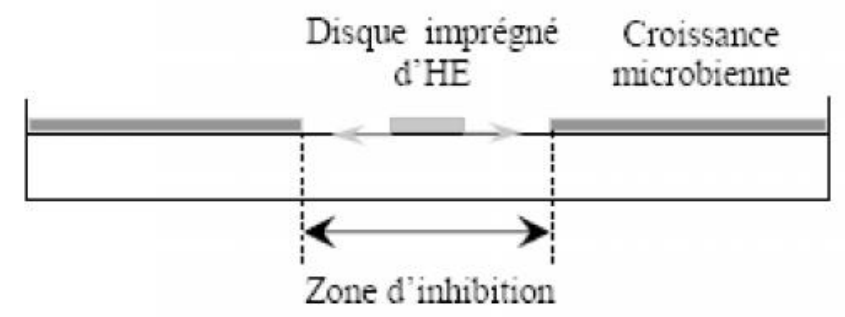

Fig.8. Aromatogramme sur boite de pétri à diffusion linéaire à partir d'un disque imprégné d'huile essentielle

\subsection{Les microorganismes testés}

Le nombre de microorganismes testés, lors de cette étude est de 8 souches dont 6 souches bactériennes ( $3 \mathrm{Gram}+$ et $3 \mathrm{Gram}-$ ) et 2 levures, appartenant à des familles différentes : Enterobacteriaceae, Enterococcaceae, Pseudomonadaceae, Saccharomycetaceae, Cryptococcaceae, provenant de la collection du laboratoire de microbiologie du Centre de Recherche et Développement de SAIDAL. Trois souches bactériennes parmi les six testées ont un pouvoir pathogène d'un niveau 2 sur une échelle structurée de 4 niveaux, établie par l'organisme ATCC (American Type Collection Culture) et deux parmi les six bactéries sont considérées comme souches test selon le même organisme (ATCC, 2004). La liste des souches est regroupée dans le Tableau 9, l'essai d'inhibition est réalisé sur des cultures pures. 
Tableau 9. Liste et caractéristiques des microorganismes testés.

\begin{tabular}{|c|c|c|c|c|c|}
\hline $\begin{array}{l}\text { Nom de la } \\
\text { souche }\end{array}$ & $\begin{array}{c}\mathbf{N}^{\circ} \\
\text { ATCC }\end{array}$ & Gram & $\begin{array}{c}\text { Souche } \\
\text { Pathogène }\end{array}$ & $\begin{array}{c}\text { Souche test } \\
\text { d'antibiotiques }\end{array}$ & Famille $^{*}$ \\
\hline $\begin{array}{l}\text { Staphylococcus } \\
\text { aureus }\end{array}$ & 6538 & + & $X$ & $\mathrm{X}$ & Staphylococcaceae \\
\hline $\begin{array}{l}\text { Staphylococcus } \\
\text { epidermidis }\end{array}$ & 12228 & + & & & Staphylococcaceae \\
\hline $\begin{array}{l}\text { Enterococcus } \\
\text { faecium }\end{array}$ & 6569 & + & & & Enterococcaceae \\
\hline $\begin{array}{l}\text { Pseudomonas } \\
\text { aeruginosa }\end{array}$ & 9027 & - & $\mathrm{X}$ & & Pseudomonadaceae \\
\hline $\begin{array}{l}\text { Escherichia } \\
\text { coli }\end{array}$ & 4157 & - & & $\mathrm{X}$ & Enterobacteriaceae \\
\hline $\begin{array}{l}\text { Klebsiella } \\
\text { pnemonia }\end{array}$ & 4352 & - & $\mathrm{X}$ & & Enterobacteriaceae \\
\hline $\begin{array}{l}\text { Saccharomyces } \\
\text { cerevisiae }\end{array}$ & 2601 & & & & Saccharomycetaceae \\
\hline $\begin{array}{l}\text { Candida } \\
\text { albicans }\end{array}$ & 24433 & & & & Cryptococcaceae \\
\hline
\end{tabular}

* Selon la seconde édition du « Bergey’s Manual of Systematic Bacteriology, 2001 »

\subsection{Préparation des suspensions microbiennes}

Nous avons effectué un prélèvement des souches test, provenant de l'organisme ATCC sous forme de disque lyophilisé. Ces dernières ont été inoculées dans un bouillon nutritif et incubées à $37^{\circ} \mathrm{C}$ pendant $24 \mathrm{~h}$. Les cultures ont été soumises à trois transferts successifs afin de déterminer la pureté et la viabilité de chaque souche avant emploi. Seules les souches âgées de 18 à 24 h ont été utilisées. Trois à quatre colonies ont été prélevées à l'aide d'une anse stérile et introduites dans un tube contenant de l'eau physiologique. Après une bonne agitation et homogénéisation à l'aide d'un vortex, nous avons mesuré les transmissions à une longueur d'ondes égale à $620 \mathrm{~nm}$ en employant un spectrophotomètre de marque Shimatzu 
(série visible). Les transmittances étaient comprises entre 22 et $32 \%$ pour les bactéries et 2 à $3 \%$ pour les levures, ce qui correspond à une concentration égale à $10^{7}-10^{8} \mathrm{cfu} / \mathrm{ml}$.

\subsection{Mode opératoire :}

Le test est effectué en cultivant les bactéries sur un milieu Muller Hinton (Difco) et les levures sur une gélose Sabouraud (Oxoid). Chaque boîte de pétri de $90 \mathrm{~mm}$ a reçu $20 \mathrm{ml} \mathrm{du}$ milieu de culture est ensemencée avec 1 à $2 \mathrm{ml}$ de la suspension microbienne contenant $10^{7}-$ $10^{8} \mathrm{cfu} / \mathrm{ml}$. Les disques stériles imprégnés d'HE sont déposés à la surface du milieu. Ensuite ils ont été incubés et inversés à l'obscurité dans une étuve à une température de $37^{\circ} \mathrm{C}$ durant $24 \mathrm{~h}$ pour les bactéries et $25^{\circ} \mathrm{C}$ durant $48 \mathrm{~h}$ pour les levures. La lecture des diamètres des zones d'inhibition après incubation est réalisée à l'aide d'un lecteur de zones de marque Read Biotic. Le test est répété trois fois.

\section{CONCLUSION}

L'objectif de ce travail était d'étudier un nouveau procédé d'extraction des huiles essentielles assistée par micro-ondes et de l'appliquer aux variétés d'agrumes algériennes. Notre but était d'améliorer ce nouveau système tout en diminuant les durées d'extraction, en simplifiant les protocoles opératoires et en élaborant une technique d'extraction des huiles essentielles applicable en particulier, à tout type d'agrumes et de végétaux en général.

L'extraction sans solvant assistée par micro-ondes présente de nombreux avantages pour l'obtention d'huiles essentielles de qualité comparée aux méthodes traditionnelles souvent longues et fastidieuses. La rapidité d'exécution, la spécificité du chauffage micro-ondes, l'économie d'énergie, la simplicité de mise en œuvre sont les principaux atouts de l'extraction sans solvant assistée par micro-ondes. De plus, la singularité des profils aromatiques des huiles essentielles obtenues par l'extraction sans solvant assistée par micro-ondes offre aux parfumeurs et concepteurs de nouvelles fragrances et de nouvelles perspectives de création grâce à une palette de senteurs encore plus large.

La comparaison d'un point de vue quantitatif de l'extraction sans solvant assistée par micro-ondes avec l'expression à froid et l'hydrodistillation des huiles essentielles d'agrumes a permis de mettre en évidence des différences de comportement selon la nature de la matrice. En effet, l'ESSAM est nettement plus performante, car en 30 minutes, il est possible 
d'extraire la même quantité d'huile essentielle qu'en 180 minutes d'hydrodistillation ou 90 minutes avec l'expression à froid.

D'un point de vue qualitatif une importante variabilité a été observée dans les proportions de la fraction oxygénée selon la technique d'extraction utilisée. Les huiles essentielles obtenues par ESSAM sont, dans tous les cas, beaucoup plus riches en composés oxygénés, composés nettement plus valorisables sur le plan olfactif. La variabilité chimique a aussi été observée par analyse statistique. Cette étude a permis d'obtenir une meilleure séparation des groupes préalablement constitués par les huiles essentielles extraites par micro-ondes, hydrodistillation ou expression à froid.

Aucune innovation technologique ne saurait prétendre à un transfert à l'échelle industrielle sans être économiquement réaliste. On reproche souvent aux technologies nouvelles d'être onéreuses. Il est indéniable que la nouveauté induit un coût d'entrée, mais qui s'atténue dans le temps et le développement de la technologie. Ce fut le cas par exemple de l'extraction par $\mathrm{CO}_{2}$ supercritique dont la viabilité économique est désormais démontrée par les nombreuses applications industrielles dans le domaine des extraits aromatiques. C'est en train de devenir le cas pour les procédés d'extraction assistée par micro-ondes.

\section{RÉFÉRENCES}

[1] Chemat F, Smadja J, Lucchesi M E. Lösungsmittelfreie Mikrowellen- Extraktion von flüchtigen Naturstoffen. Brevet Européen, EP 1439218 A1, 2004.

[2] Chemat F, Smadja J, Lucchesi M E . Solvent-free microwave extraction of volatile natural substances. Brevet Américain, US 2004/0187340 A1, 2004.

[3] Ferhat M A, Meklati B Y Smadja J, Chemat F. An improved microwave Clevenger apparatus for distillation of essential oils orange peel. J.Chromatogr. A., 2006, 1112, 121-126, doi:10.1016/j.chroma.2005.12.030

[4] Recueil des normes françaises : Huiles essentielles. Editions AFNOR, Paris, 2000.

[5] Conner D E, Beuchat L R. Effects of essential oils from plants on growth of food spoilage yeasts. J. Food Sci., 1984, 49, $429-434$.

[6]Adam K, SivropoulouI A, Kokkini S, Lanaras T, Arsenakis M. Antifungal Activities of 
Origanum vulgare subsp. Hirtum, Mentha spicata, Lavandula augustifolia, and Salvia fruticosa Essential Oils against Human Pathogenic Fungi. J. Agric. Food Chem., 1998, 46(6), 1739-1745.

[7] Chao S C, Young D G, Oberg G J. Screening for Inhibitory Actvity of Essential Oils on Selected Bacteria, Fungi and Viruses. J. Essent. Oil Res., 2000, 12, 639-649.

[8] ANDREWS J.M. The Development of the BSAC standardized method of disc diffusion testing. J. of Antimic. Chemo., 2001, 48, Suppl. S1, 29-42.

[9] Ela M A, El-shaer N S, Ghanem N B. Antimicrobial evaluation and chromatographic analysis of some essential and fixed oils. Pharmazie., 1996, 51, 993 - 995.

[10] Meena M R, Sethi V. Antimicrobial activity of the essential oils from spices. J. Food Sci. and Tech. Mysore., 1994, 31, 68 - 70.

[11] Deans S G, Ritchie G. Antimicrobial Properties of Plant Essential oils. Int.J. of Food Microbiol.,1987, 5, 165-180.

[12] Deans S G, Noble R C, Hiltunen R, Wuryani W, Penzes L G. Antimicrobial and antioxidant properties of Syzygium aromaticum (L.) Merr. \& Perry: impact upon bacteria, fungi and fatty acid levels in ageing mice. Flav. Fragr. J.,1995, 10, 323 - 328.

[13] Dorman H J, Deans S G. Antimicrobial agents from plants: antibacterial activity of plant volatile oils. J. Appl. Microbiol., 2000, 88: 308-316.

[14] Kivanc M, Akgul A. Antibacterial activities of essential oils from Turkish spices and citrus. Flav. Fragr. J.,1986, 1, 175-179.

[15] Tassou C C, Nychas G J E. Antimicrobial activity of the essential oil of mastic gum (Pistacia Lentiscus Var Chia) on gram positive and gram negative Bacteria in both and in model food system. Int. Biodeterior.Biodegrad.,1995, 36, 411-420.

[16] Mann C M, Cox S D, Marham J L. The outer membrane of pseudomonas aeruginosa NCTC6749 contributes to its tolerance to the essential oil of Melaleuca alternifolia (tea tree oil).Lett. Appl. Microbiol., 2000, 30, 294-297.

[17] Inouye S, Takizwa T, Yamaguchi H. Antibacterial Activity of Essential oils and Their Major Constituents Against Respiratory Tract Pathogens by Gaseous Contact. J. Antimi. Chemo., 2001, 47, 565-573. 
[18] Farag R S, Daw Z Y, Hewedi F M, El-baroty G S A. Antimicrobial Activity of Some Egyptian Spice Essential Oils. J. Food Protec.,1989, 52(9), 665 - 667.

[19] Jumenter I. Les huiles essentielles des citrus et leur utilisation en parfumerie. Thèse de Doctorat d'État, Université de Limoges, France, 1984.

[20] Buccelato F. Orange blossom. Perfumer and Flavorist., 1981, 3, 31-34.

[21] Clevenger J F. Amer. Perf. Essent. Oil Rev., 1928, 467.

[22] Di giacomo A. Huiles essentielles d'agrumes et fraudes : les méthodes de détection. Labo Pharma. Problèmes et Techniques., 1978, 277, 508-514.

[23] Adams R P. Identification of essential oil components by gas chromatography / mass spectroscopy, Allured Publishing Corporation, Carol Stream, 1995.

\section{How to cite this article:}

Ferhat M A, Boukhatem M N, Hazzit M, Chemat F. Rapid Extraction of Volatile Compounds from Citrus Fruits using a Microwave dry Distillation. J. Fundam. Appl. Sci., 2016, 8(3), 753-781. 